\title{
REDES SOCIAIS VIRTUAIS: TERRITÓRIOS ABERTOS PARA A HISTÓRIA DA EDUCAÇÃO
}

\author{
Robson Fonseca Simões \\ Universidade Federal de Rondônia/UNIR \\ fonsim2000@ hotmail.com
}

\section{RESUMO}

As práticas discursivas que permeiam o nosso cotidiano nas mais diferentes instâncias de socialização têm sido exploradas como locus privilegiado de investigação nas mais diversas áreas científicas: linguística, antropologia, psicologia, literatura etc. A História da Educação também entra em cena nesses estudos, propondo tornar mais visíveis os caminhos da construção da memória ou das memórias que nos constituem como sujeitos históricos. Assim, busca-se neste texto, analisar algumas escritas dos ex-alunos do colégio Pedro II, uma instituição pública da cidade do Rio de Janeiro, mais especificamente, na categoria escolas e cursos na comunidade do Orkut, procurando espiar por uma fresta os horizontes de sentidos nas narrativas que contam as histórias daqueles sujeitos. Nesse sentido, traz para o debate as escritas virtuais considerando-as fontes historiográficas para o campo da História da Educação. Por que as escolas percorrem o espaço virtual? Os depoimentos criam chances para analisar os usos e as funções da cultura escrita, descrevendo nas entrelinhas midiáticas outras histórias que perpassam a vida escolar. Valho-me dos estudiosos Chartier (2007), Alberca (2000), Muzart (1998), Certeau (1982), Lévy (1999), Nunes (2005) e Le Goff (1984) para me ajudar a pensar que os sujeitos também se constroem nos mais diversos suportes de escrita.

Palavras-chave: Memórias Escolares. Redes Sociais do Orkut. História da Educação.

\section{SOCIAL NETWORKING: OPEN TERRITORIES FOR THE HISTORY OF EDUCATION}

\begin{abstract}
The discursive practices that permeate our daily lives in many different instances of socialization have been explored as a privileged locus of research in several scientific areas: linguistics, anthropology, psychology, literature etc. Now the History of Education also comes into play in these studies, proposing to make more visible the memory construction of roads or the memories that constitute us as historical subjects. Thus search in this text, look at some writings of the former students of the college Pedro II, a public institution in the city of Rio de Janeiro, more specifically in the category schools and courses in the Orkut community, trying to peer through a crack the horizons of felt in the narratives that tell the stories of those guys. In this sense, it brings to the debate virtual written considering the historiographical sources for the field of History of Education. Why schools run the virtual space? The statements create chances to analyze the habits and culture of writing functions, describing the lines other media stories that permeate school life. I make use of Chartier scholars (2007), Alberca (2000), Muzart (1998), Certeau (1982), Lévy (1999), Nunes (2005) and Le Goff (1984) to help me think that the subjects also construct written in various media.
\end{abstract}

Keywords: School Memories. Social Networking Orkut. History of Education. 
Nós pensamos no mundo da mesma maneira que falamos sobre ele [...], talvez o melhor caminho para os historiadores da cultura entender a comunicação e interpretá-las, seja pensar nos símbolos como polissêmicos, fluidos e complexos.

Robert Darnton

\section{INTRODUÇÃO}

As práticas discursivas que permeiam o nosso cotidiano nas mais possíveis instâncias de socialização têm sido exploradas como locus privilegiado de investigação por pesquisadores das mais diversas áreas científicas: linguística, antropologia, psicologia, literatura etc. Ora, a história da Educação também entra em cena nesses estudos, propondo tornar mais visíveis os caminhos da construção da memória ou das memórias que nos constituem como sujeitos históricos. Nesse sentido, este estudo, um mergulho na minha tese de doutoramento, procura trazer para o debate a investigação e difusão dos arquivos escolares e de arquivos pessoais na história da Educação.

A escrita, conjunto linguístico utilizado no contexto social e na vida, constitui-se uma das possibilidades do sujeito histórico registrar as suas práticas, experiências, ideias, acontecimentos, ou seja, representações de um tempo vivido. Escrever, portanto, se constitui uma produção de memória, e, por conseguinte, um instrumento para rever o passado. Chartier (2007, p. 94) lembra que, por meio da escrita, em seus vários suportes, são fixados os "traços do passado, a lembrança dos mortos, ou a glória dos vivos”.

Este trabalho é fruto de um esforço em lidar com as escritas de si efêmeras na web, isto é, linguagens desenvolvidas com movimentos velozes no ato de escrever. Assim, buscase nesse texto, analisar algumas escritas dos ex-alunos do colégio Pedro II, uma instituição pública de ensino médio e fundamental, na cidade do Rio de Janeiro, mais especificamente na categoria escolas e cursos na comunidade do Orkut $^{l}$ Colégio Pedro II, Engenho Novo, nos fóruns: E as greves em 67/68? E o fechamento do grêmio?; Comunidades do Marcondes, procurando espiar por uma fresta os horizontes de sentidos nas narrativas que contam as histórias daqueles sujeitos, nos seus cotidianos e nas suas práticas escolares. Neste sentido, traz para o debate as escritas virtuais considerando-as fontes historiográficas para o campo da história da Educação. Por que as escolas percorrem o espaço virtual? Mas, por que estudar estas escritas no Orkut da web? Que significados históricos podem ser entendidos com esses discursos na internet?

\footnotetext{
${ }^{1}$ Rede de sociabilidade da internet.
} 
As escritas de si no espaço virtual podem nos oferecer pistas ao compreender as práticas culturais de uma época com técnicas cada vez mais sofisticadas em lidar com o ritmo veloz, enfatizando as redes de sociabilidade, entrecruzando fatos e tempos, o que certamente possibilita a formação de um campo fértil em estudos da história da educação. E quais as memórias da escola mais recorrentes nas escritas que falam de si na rede?

Muzart (1998) afirma que a internet abre um caminho para um terceiro modo de comunicação, de verdadeiro diálogo e com uma dimensão coletiva. Nesse sentido, a web criou laços, possibilitando o exprimível sem amarras ou censuras; e os espaços digitais também fazem a sua parte, espalhando na rede, memórias de um passado, tornando-se escritas sem um destinatário designado, rompendo com a noção de segredo, de intimidade. Nesta acepção, o Orkut pode ser entendido como um novo suporte da escrita na tela do computador.

As palavras de Chartier (1997, p. 124) corroboram a importância de trazer para o debate as escritas do universo virtual: "Com o texto eletrônico, enfim, parece estar ao alcance de nossos olhos e de nossas mãos um sonho muito antigo da humanidade, que se poderia resumir em duas palavras, universalidade e interatividade". Neste sentido, podemos supor uma nova caracterização do leitor/escritor diante do advento do hipertexto eletrônico;

A leitura é sempre apropriação, invenção, produção de significados [...] o leitor é um caçador que percorre terras alheias. Apreendido pela leitura, o texto não tem de modo algum - ou ao menos totalmente - o sentido que lhe atribui seu autor, seu editor ou seus comentadores. Toda história da leitura supõe, em seu princípio, essa liberdade do autor que desloca e subverte aquilo que o livro lhe pretende impor. Mas esta liberdade leitora não é jamais absoluta. (CHARTIER, 1999, p. 149).

E com a proliferação de documentos para a pesquisa em história da educação, surgem novas questões para nos ajudar a pensar sobre as fontes historiográficas, arquivos e os documentos históricos: qual o tipo de relação essas fontes historiográficas têm com os grupos que constituímos?

As grandes mudanças sociais e culturais levadas a efeito ao longo do século $\mathrm{XX}$, em especial na segunda metade do século, permitem afirmar que os escritos em diários virtuais, ou espaços que possibilitam o sujeito registrar suas experiências, é crescente. Com o surgimento da internet, essa prática de escrita migrou para novas mídias, como blogs, fotologs, orkut, you tube, páginas na rede abertas à leitura de qualquer pessoa. Assim, esses dispositivos tecnológicos instauram novas formas de sociabilidade e novos modos de escritas pessoais, e assim, registram uma época de textos eletrônicos com as histórias não oficiais, em outras palavras, escritas dos sujeitos com versões que não estariam registradas nas fontes das autoridades constituídas na escola. 
Verifica-se que há histórias oficiais nos estabelecimentos de ensino, registradas nos mais diversos documentos: diários, protocolos, certificados, arquivos que legitimam as vozes dos dirigentes escolares. É possível encontrar outras versões de escritas, não necessariamente articuladas com os registros dos dirigentes. O que não significa uma instância de verdade na produção dessas escritas, contudo, nos convida à reflexão para compreender outras práticas de escritas escolares. Talvez apreender alguns silêncios materializados, nos ajude a pensar que o silêncio também fala.

É possível refletir que as escritas escolares são registros impostos pelos seus respectivos dirigentes, contudo os alunos subvertem a ordem, a disposição, criando suas próprias anotações, que não são oficiais, em outros espaços escolares, para materializarem os seus pensamentos. Neste sentido, as últimas folhas do caderno, as portas do banheiro da escola, as primeiras páginas do livro escolar, as carteiras e cadeiras escolares podem também oferecer materialidades para registrarem os apelos dos sujeitos no tempo de escola.

E a postagem no Orkut $^{2}$ também é um espaço que os sujeitos compartilham com as suas diferentes histórias. Tentando pensar este espaço virtual como registro de vida que guarda traços culturais de uma época, o historiador pode investir na interpretação de seus conteúdos, observar as formas de registro dos acontecimentos que contribuem para a compreensão de um passado na escola, como se pode examinar a seguir.

\footnotetext{
${ }^{2}$ O Orkut é uma rede social filiada ao Google, criada em 22 de janeiro de 2004, com o objetivo de ajudar um membro - usuário da internet - a criar novas amizades e relacionamentos. Este espaço virtual é organizado por redes de familiaridades. A entrada nesse espaço pode ou não ser franqueada pela apresentação de um membro mais antigo. Uma vez convidado, o novo membro organiza a sua própria página, incluindo seus dados. Nessa organização, está em jogo tanto o modo como o sujeito/membro/usuário se vê, quanto o modo como deseja ser visto por aqueles que acessarem sua página.
} 
Figura 1: página inicial da comunidade Colégio Pedro II - Engenho Novo.

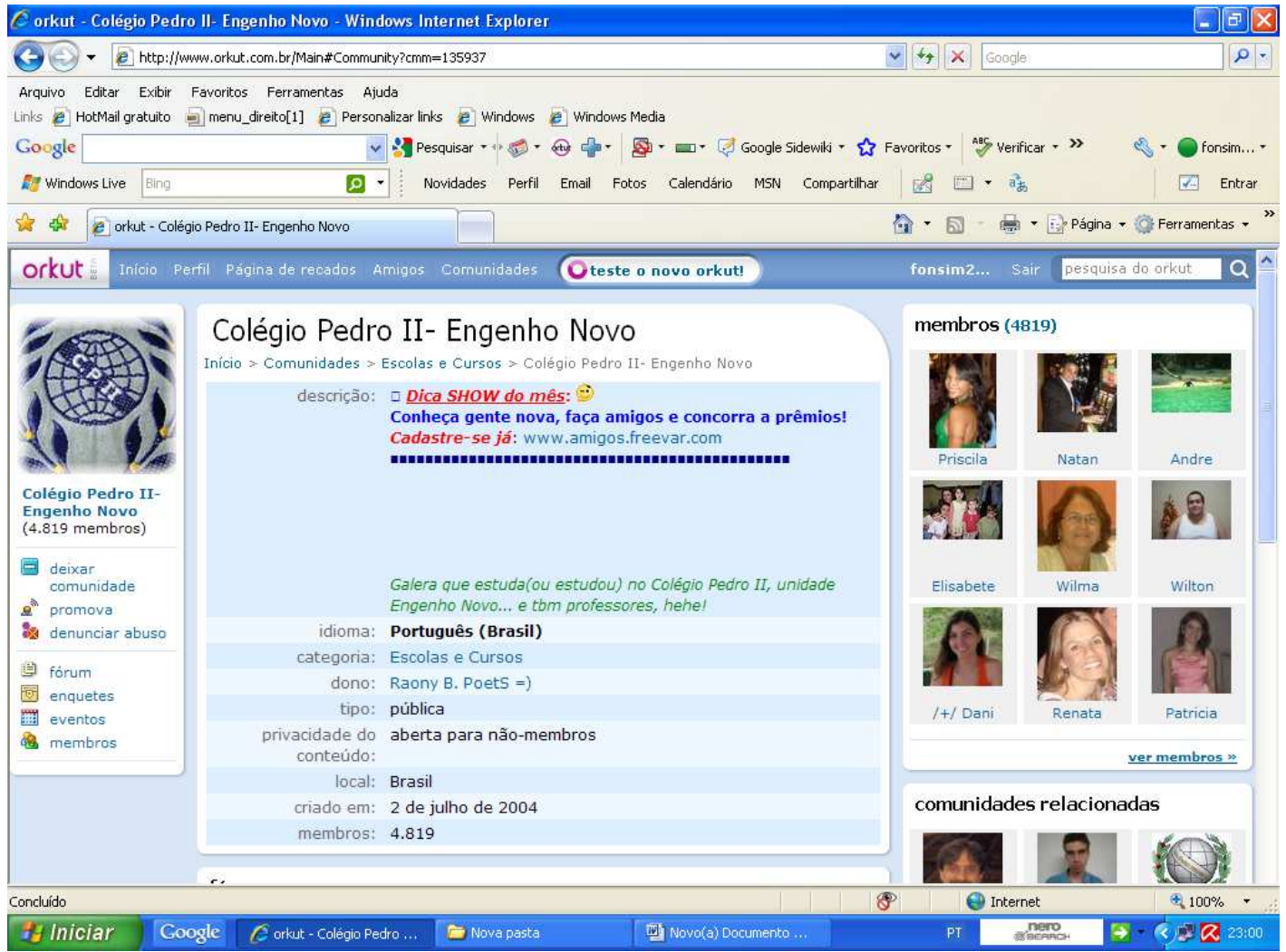

Fonte: Comunidades do Orkut.

Observa-se a página inicial da comunidade do Orkut ${ }^{3}$ do Colégio Pedro II - Engenho Novo inserida na categoria escolas e cursos. O criador e o administrador dos novos acessos é Raony B. Poets. Ele criou esse espaço no dia 2 de julho de 2004, e permitiu a privacidade do conteúdo aberta para não-membros, o que possibilita qualquer usuário da internet visitar e acompanhar as memórias da comunidade. Esse fato me chamou atenção, uma vez que é comum outros moderadores de diversas comunidades só permitirem acesso apenas para os usuários que fazem parte daquele contexto.

Acessada no dia 27 de dezembro de 2009, percebi uma página com 4819 membros, mostrando-nos um número considerável de sujeitos que um dia fizeram ou fazem parte da história daquela instituição de ensino. São atores sociais trazendo na escrita marcas da instituição federal de ensino no Rio de janeiro, Colégio Pedro II. Mas o que aquele espaço traz de memória da escola? Podemos considerá-lo documento? O que ele preserva? O que se produz?

\section{DOCUMENTOS E HISTÓRIA: DIÁLOGOS COM A MEMÓRIA}

\footnotetext{
${ }^{3}$ Endereço eletrônico: <http://www.orkut.com.br/Main\#Community?cmm=135937>.
} 
A pesquisa histórica nos conduz a caminhos insólitos, desconhecidos, entrecortados, interrompidos, nos levando a lugares inabituais, e o historiador é o que se deixa levar por esses ziguezagues, atento às fontes historiográficas, se prontificando na tarefa de significar, traduzir os sentidos nos mais variados caminhos. Certeau (1982, p. 86) nos reforça a compreensão de que a história começa com gestos e separação, reunião e transformação em "documentos", de certos objetos que ganham nova distribuição num espaço. Deste modo, o trabalho do pesquisador começa quando a partir de um campo já produzido, opera novos recortes e descobertas, numa investigação epistemológica que inclui o trabalho com a interpretação.

Aquele que pesquisa consegue perceber a complexidade e a pluralidade ao lidar com a memória; analisar os fatos ocorridos, identificar os episódios e refletir sobre o passado são ações que exigem um grande esforço por manusear, examinar e fundamentar a escrita da história. Nunes (2005, p. 182) nos ajuda a refletir que mapear fontes é, portanto, preparar o terreno para uma crítica empírica vigorosa, constituindo novos problemas, novos objetos e novas abordagens; a figura abaixo nos reserva esta ideia.

Figura 2: Comunidade Colégio Pedro II- Engenho Novo.

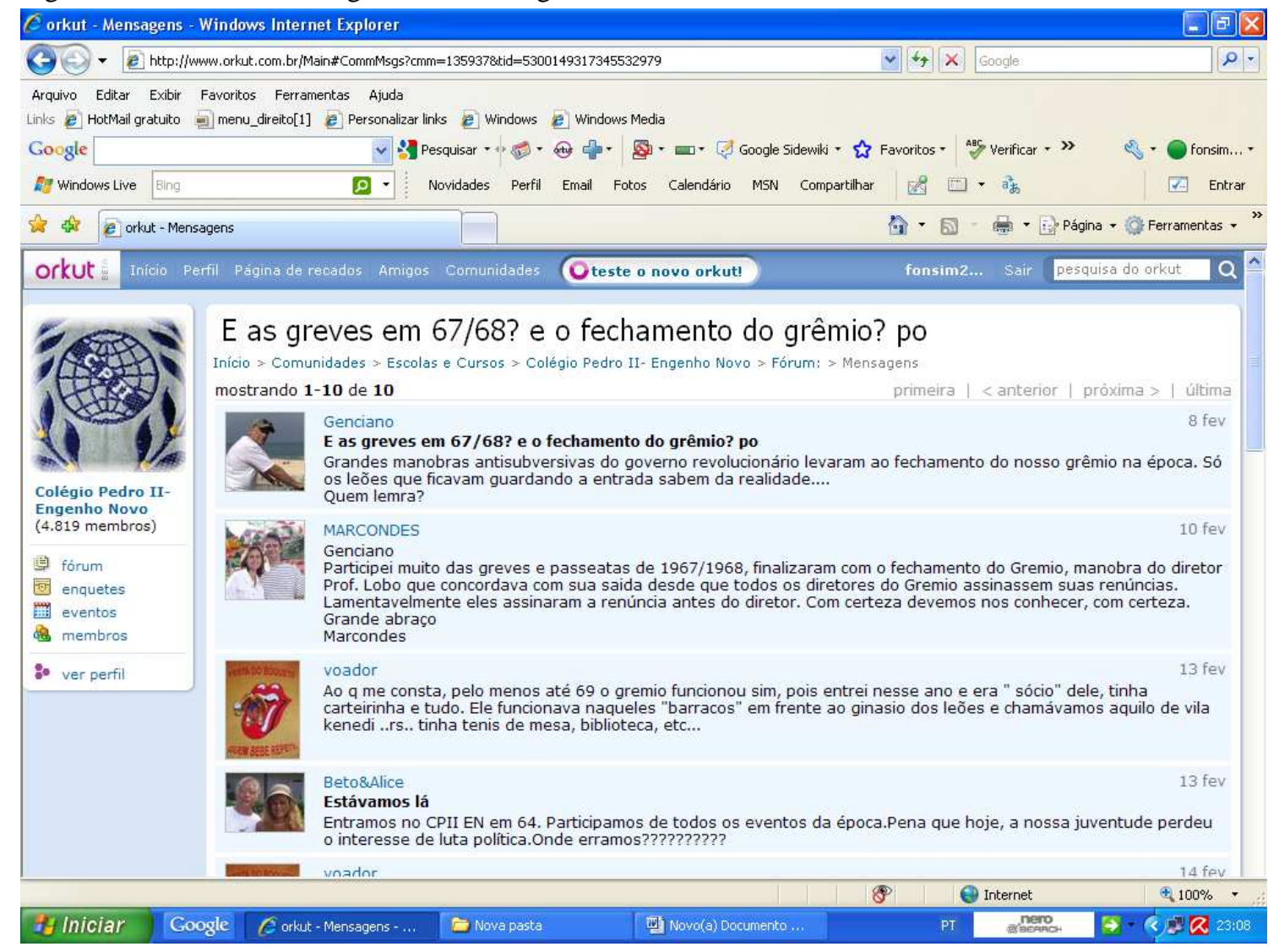

Fonte: Fórum $E$ as greves em 67/68? E o fechamento do Grêmio? 
Para a História da Educação, é possível pensar que essa memória escrita no Orkut permitiu buscar traços de como foram representadas as vivências de momentos da vida cotidiana escolar, e até nos aspectos políticos comentados por Genciano, como se observa acima na figura 2 . A sua escrita no fórum ${ }^{4}$ revela as memórias da história estudantil no grêmio do Colégio Pedro II, Engenho Novo, entre os anos de 1967/1968, enfatizando as manobras políticas que levaram o fechamento daquele grêmio. Além dessa escrita, observa-se Marcondes, neste mesmo tópico, anunciando que também participou daquele movimento de greve, e das passeatas que finalizaram com o fechamento do grêmio estudantil.

Os relatos de Voador permitem, numa análise historiográfica, tentar compreender aspectos geracionais (por meio do vocabulário utilizado ou da menção de hábitos e vivências cotidianas) e também do momento histórico político vivido pelos alunos, em especial, pela escola. Assim, compreendo que além da materialidade do suporte eletrônico e pelos fatos narrados, as escritas com as reflexões feitas pelos sujeitos sobre política, greve, também podem ser do interesse do historiador, pois são momentos em que o cotidiano e o ordinário se unem como uma parte constitutiva das experiências humanas.

Esses materiais como fontes historiográficas também possibilitam estudar as formas de linguagem utilizadas, as maneiras de narrar em uma determinada época, os usos e apropriações da língua e outros aspectos que revelam as transformações históricas nas tecnologias de escrita, que interessam à história da cultura escrita. Certeau (1982, p. 78) ajuda a refletir que os discursos são emitidos de um dado lugar, que deve ser interrogado pelo historiador: um lugar temporal, espacial, institucional; um lugar de fala ou de autoria; um lugar social. É possível observar, por exemplo, na escrita de Voador, na figura 2, os signos recorrentes do universo virtual: $r s ; q$.

Ora, se a mão do sujeito incansavelmente deslizava sobre folhas, cadernos, num tempo digital, move-se sobre teclados, telas, também deixando marcas históricas de uma vida, escritas pessoais, experiências individuais, assim, acredito ser de muita relevância um encaminhamento de estudos sobre a questão das escritas que falam de si na web e suas respectivas análises históricas.

Se os estudos autobiográficos de Alberca (2000, p. 156) sobre as escritas dos diários íntimos são consideradas pelo autor invisíveis, destaco aqui a minha compreensão de que essas escritas das práticas escolares no Orkut são visíveis, em outras palavras, manifestas, contendo a caixa preta das práticas escolares.

\footnotetext{
${ }^{4}$ Uma das páginas na comunidade do Orkut.
} 
Chartier (2000, p. 184) propõe um novo olhar para a história cultural ${ }^{5}$, tornando viável encontrar modelos de inteligibilidade em vizinhos que até aí os historiadores tinham frequentado pouco. Assim, sucederam-se novas alianças obrigando os pesquisadores dos mais variados campos perceberem que as leituras dos diferentes textos são vistas não como singularidades individuais, mas possibilidades para decifrar a expressão inconsciente de uma sensibilidade coletiva, ou para encontrar representações espontâneas e universalmente partilhadas.

E quando o norte da pesquisa é a história do tempo presente, é possível o historiador dialogar com as reflexões de Rolland (2004, p. 19). Elas nos permitem entender que sites da internet dos Ministérios das Relações Exteriores de um conjunto de países, particularmente da França e do Brasil, foram concebidos como instrumentos práticos e vitrines, sendo utilizados por estudantes e historiadores como fontes de preservação e de reconstrução da memória, contribuindo, assim, como fontes de informação e documentação privilegiadas na história das relações diplomáticas contemporâneas.

No prosseguimento dessa reflexão, se vivemos num impacto de revoluções tecnológicas das mais variadas ordens documentais e de uma enorme ampliação de memórias históricas, não é possível permanecer com olhos vendados para o universo contemporâneo. Nunes (1987, p. 46) nos ajuda a pensar que nós ainda não exploramos sequer a quarta parte de um mar de documentos que nos ameaça afogar, criando múltiplas pistas e que nos obrigam a sucessivos mergulhos. Neste sentido, proponho novos olhares no campo do pesquisador em história da educação que não poderão desconsiderar as questões teórico-metodológicas utilizadas por essas novas fontes historiográficas.

Se os diários de viagem, correspondências, relatórios de diretores, de professores, memoriais, desenhos e fotografias aguardam o olhar atento dos pesquisadores da história da educação, por que não as páginas da internet podem fazer parte do repertório de textos que contribuem para a investigação da história da educação? Le Goff (1984, p. 146) faz referência, quando considera o trabalho de seleção e valoração do historiador diante dos produtos de uma montagem produzida e conservada no esforço de legar certas imagens ao futuro. Assim, é possível perceber que esses documentos são monumentos, testemunhos e criadores de muita importância para a história da educação.

Nas suas reflexões acerca da historicidade do campo da história da Educação, Nunes (2005) nos ajuda a pensar que se apanharmos ao acaso livros dedicados à história da

\footnotetext{
${ }^{5}$ A partir da década de 1970, Burke (1978) procura explicar a emergência de se dialogar historicamente com os aspectos culturais do comportamento humano (linguagem, indumentária, culinária).
}

Rev. Iberoam. Patrim. Histórico-Educativo, Campinas (SP), v. 1, n. 1, p. 111-127, jul./dez. 2015 
educação, é possível perceber que estas obras a apresentam ora pela lente da organização escolar, ora pela lente do pensamento pedagógico, ora pela lente que concilia as duas perspectivas. Assim, inquieta-nos propor outras questões que nos aproximem de uma trajetória fértil em possibilitar um mergulho atento e sensível ao detalhamento e expansão dos tempos escolares na pesquisa da história da educação, a partir de escritas ordinárias que recontam as vidas escolares.

E quando o tema é internet, compreendo-a como uma rede capaz de interligar todos os computadores do mundo ${ }^{6}$. O final do século XX nos deixou um legado com a popularização dos dispositivos portáteis, com um grande interesse no estudo da mobilidade em sistemas de computação. A computação móvel, na década de 90, introduziu o uso de dispositivos portáteis e recursos computacionais via telefones celulares. É a sofisticação tecnológica associada à visão de um futuro baseado no usuário: o cenário da computação pervasiva ${ }^{7}$ chega aos nossos olhos como um sistema tecnicamente disponível, independente de dispositivos, localização e tempo. Nesse novo ambiente computacional, a comunicação é centrada no usuário e não no dispositivo isolado. Nessa assertiva, o campo das novas tecnologias é, como diz Lévy (1999, p. 34), "Um campo aberto, conflituoso e parcialmente indeterminado, no qual nada está decidido a priori”. Nesse campo, não há imutabilidade, mas constantemente novas conexões imprevisíveis. Qual a relação da história com esse tempo tecnológico?

Os estudos de Faria Filho e Bertucci (2009) nos possibilitam a encaminhar algumas questões acerca da experiência e cultura escolar: é possível fazer uma história da experiência escolar? Como captar as experiências dos sujeitos na escola? Talvez as escritas que falam de si na internet possam nos ajudar a interrogar um passado, possibilitando entender mais sobre a história da experiência escolar.

Abaixo foi estruturado um quadro cujo objetivo é nos auxiliar a encontrar os tópicos ${ }^{8}$ com o maior número de postagens no Fórum da comunidade Pedro II - Engenho Novo ${ }^{9}$, em

\footnotetext{
${ }^{6}$ Parecida com o sistema telefônico internacional, ninguém é proprietário ou controlador de todo o sistema, mas ele está conectado de tal maneira, que o faz funcionar como uma grande rede. O que faz a internet tão poderosa assim é a linguagem que atende pelas siglas TCP/ IP (Protocolo de Controle de Transferência). Todos os computadores que entendem essa língua são capazes de trocar informações entre si. Assim, podemos conectar máquinas de diferentes tipos, como Pcs, Macs e Unix. Se você pretende acessar um computador no Japão, por exemplo, basta conectar-se a um computador ligado à internet na sua cidade. Os provedores internet podem oferecer vários serviços. Os usuários copiam arquivos, enviam mensagens para outros usuários, participam de grupos de discussão etc.

${ }^{7}$ AUGUSTIN, Iara. Comunicação entre Componentes da Aplicação em Ambiente Pervasivo. Núcleo de Ciência da Computação. Universidade Federal de Santa Maria (UFSM).

${ }^{8}$ Vale lembrar que a cada participação nova no tópico com uma nova escrita, o sistema atualiza a data da última postagem.

${ }^{9}$ Observado em 27/12/2009.
} 
outras palavras, espiar os tópicos que mantêm uma expressiva participação de experiências escolares.

\begin{tabular}{|c|c|c|c|c|c|}
\hline $\begin{array}{c}\text { Número de } \\
\text { postagens }\end{array}$ & Tópicos & Comunidade & Tema & $\begin{array}{l}\text { Primeira } \\
\text { postagem }\end{array}$ & Autor \\
\hline 101 & $\begin{array}{l}\text { Quem foi } \\
\text { aluno do } \\
\text { Prof. } \\
\text { Dornellas de } \\
\text { desenho? }\end{array}$ & $\begin{array}{l}\text { Colégio } \\
\text { Pedro II- } \\
\text { Engenho } \\
\text { Novo }\end{array}$ & $\begin{array}{c}\text { Professor } \\
\text { querido } \\
\text { pelos alunos }\end{array}$ & $23 / 12 / 2004$ & $\begin{array}{l}\text { Victor } \\
\text { Hugo }\end{array}$ \\
\hline 43 & $\begin{array}{l}\text { Alunos do } \\
\text { “crepúsculo" } \\
\text { do CPII do } \\
\text { Engenho } \\
\text { Novo } \\
\end{array}$ & $\begin{array}{l}\text { Colégio } \\
\text { Pedro II- } \\
\text { Engenho } \\
\text { Novo }\end{array}$ & $\begin{array}{l}\text { Curso } \\
\text { noturno }\end{array}$ & $18 / 11 / 2005$ & Marilda \\
\hline 26 & $\begin{array}{c}\text { Quem } \\
\text { gostava de } \\
\text { Lycia } \\
\text { Maria? }\end{array}$ & $\begin{array}{l}\text { Colégio } \\
\text { Pedro II- } \\
\text { Engenho } \\
\text { Novo } \\
\end{array}$ & $\begin{array}{l}\text { Professora } \\
\text { que } \\
\text { vistoriava } \\
\text { cadernos }\end{array}$ & $08 / 10 / 2004$ & Carlito \\
\hline 10 & $\begin{array}{c}\text { E as greves } \\
\text { em } 67 / 68 ? \mathrm{E} \\
\text { o } \\
\text { fechamento } \\
\text { do grêmio? }\end{array}$ & $\begin{array}{l}\text { Colégio } \\
\text { Pedro II- } \\
\text { Engenho } \\
\text { Novo }\end{array}$ & $\begin{array}{c}\text { Greves e } \\
\text { passeatas de } \\
1967 / 1968\end{array}$ & $08 / 02 / 2009$ & Genciano \\
\hline
\end{tabular}

Fonte: Elaborado pelo autor (2013).

Talvez seja interessante neste momento trazer à tona algumas leituras importantes do Colégio Pedro II, Engenho Novo; versões essas construídas por outros autores, portanto, com sentidos diversos. Não perdendo de vista que há muitos debates e discussões acerca da história dessa instituição de ensino, neste estudo, eu me limito às reflexões das escritas da web ${ }^{10}$ sobre a instituição.

O Colégio Pedro II é uma tradicional instituição de ensino público federal, localizada no estado do Rio de Janeiro. É o segundo mais antigo dentre os colégios em atividade no país e conta com 12 unidades escolares na cidade do Rio de Janeiro nos bairros do Centro, São Cristóvão (3 unidades), Humaitá (2 unidades), Tijuca (2 unidades), Engenho Novo (2 unidades) e Realengo ( 2 unidades). Também possui uma unidade em Niterói e outra em Duque de Caxias. Esta instituição de ensino ministra o ensino fundamental, o ensino médio e

${ }^{10}$ Ver em: <www.educacao.ufrj.br/artigos/n6>. 
o ensino técnico nas modalidades médio, integrado e PROEJA ${ }^{11}$. Nos últimos anos, o Colégio Pedro II vem sofrendo importantes transformações. Criou novas unidades, inclusive fora da capital, e realizou mudanças internas, de natureza pedagógica e administrativa. Na página eletrônica do Colégio encontra-se definida, em 2008, a seguinte "missão": Educar crianças e adolescentes, tornando-os capazes de responder às transformações técnicas, culturais, emocionais e sociais do mundo de hoje. Talvez seja interessante notar a presença das expressões "transformações" e "mundo de hoje". Elas atuam como um contraponto à imagem ainda difundida de escola conservadora, do ponto de vista pedagógico e administrativo, e que muitas vezes é associada à sua tradição de escola secular.

\section{MEMÓRIAS DIGITAIS: ESCRITAS DE SI NA INTERNET}

A palavra traz consigo um poder libertador, criador. Ela também navega num tempo híbrido, polifônico e digital com recursos tecnológicos que dialogam com a tríade: memória, linguagens e história para acompanhar caminhos, estradas de vidas protagonizadas na escola ou fora dela, numa cadeia infinita de expressões, sentimentos e subjetividade.

Num tempo cada vez mais digital, memória e história estão num encadeamento inacabado para recriação, no plano da arte e da linguagem, assim como Chartier (1987, p. 75) explicita que uma obra não tem sentido estático, universal e fixo, ela confere outros tipos de significações plurais e móveis para sublinhar a vida cotidiana dos sujeitos. Portanto, o entusiasmo e a subjetividade criam asas, decolando num universo ambicioso saturado de conclusões, onde sujeitos encontram novas estratégias narrativas editadas com o auxílio das tecnologias, para nos convidar a compreender as suas tramas de vida.

Muzart (1998) nos faz refletir que a internet resgata o gosto de ler e de escrever, apesar de afastar o usuário da máquina da página branca de papel, ligando-o à escrita no branco do vídeo, num ato de liberdade, escrevendo para partilhar os momentos de vida, as alegrias e o prazer. Nessa acepção, quiçá, observar outras comunidades que esses ex-alunos estão vinculados no Orkut, nos possibilite entender mais sobre a trajetória pessoal ou profissional desses usuários da comunidade do Colégio Pedro II, Engenho Novo. Dentre as comunidades que Marcondes participa, por exemplo, estão: Relatos de Mergulhos Caça Sub, Rio Antigo/ Cidade Maravilhosa, Morro de Saudades do CPII, como podemos ver a seguir.

\footnotetext{
11 Programa Nacional de Integração da Educação Profissional com a Educação Básica na Modalidade de Educação Jovens e Adultos.
} 
Figura 3: Comunidade de Marcondes Seeberger - ex-aluno do Colégio Pedro II de 67/68.

\begin{tabular}{l} 
Arquivo Editar Exibir Favoritos Ferramentas Ajuda \\
\hline$x$ Google orkut \\
\hline$x$ orkut - Comunidades de MARCONDES - Windows Internet Explorer
\end{tabular}

Fonte: Comunidade do Orkut.

É possível perceber, assim, a sua saudade do tempo de escola, ajudando-nos a pensar como a instituição marcou na vida de Marcondes. Assim, as escritas no Orkut a partir das memórias dos sujeitos no colégio Pedro II podem oferecer pistas aos historiadores da educação com informações importantes que se acumulam, produzindo sentidos para o estudo tanto da vida privada, pois mostram partes de uma história de costumes, como da vida pública, que conta a histórica greve na instituição.

Considero que as memórias individuais, coletivas e históricas se entrelaçam e podem favorecer a produção de sentidos para acompanhar trajetórias de vidas. Essa busca de sentido, talvez possa acompanhar, também, no reconhecimento da trajetória em processo, que visa articular presente, passado e futuro, num movimento de ações da vida. Mas o que podemos entender como presente, passado e futuro?

Le Goff (1990) nos ajuda a pensar que a matéria fundamental da história é o tempo; portanto não é de hoje que a cronologia desempenha um papel essencial como fio condutor da história. Observa-se que o instrumento principal da cronologia é o calendário, sendo o quadro temporal do funcionamento da sociedade. Os homens têm periodizado o tempo, num esforço 
para domesticar o tempo natural. Assim, as periodizações sociais suscitam muitos debates e questões.

Alguns linguistas nos ajudam a pensar que a construção do tempo na expressão verbal vai muito além dos aspectos verbais e diz respeito ao vocabulário, à frase e ao estilo. Reencontra-se a ideia fundamental do passado, futuro e do presente como construção, organização lógica, e não como um dado inculto.

Vendryès (1986) insistiu muito nas insuficiências da categoria gramatical do tempo e nas inconsequências que o uso dos tempos manifesta em todas as línguas: "é tendência geral da linguagem empregar o presente com a função de futuro: vou lá = irei lá; o passado pode ser também expresso pelo presente, chamado de futuro histórico: “Em 410, os bárbaros chegarão a Roma [...]" (Vendryés, 1986, p. 130).

É possível pensar que a distinção entre passado, presente e futuro é maleável e está sujeita a múltiplas manipulações. O passado depende parcialmente do presente, assim a história é contemporânea na medida em que o passado é apreendido no presente para responder ou tentar responder os interesses de um tempo presente ou que está por vir.

Bosi (2004) encaminha uma reflexão, enfatizando que quando vamos ao encontro do passado, por meio da memória, partimos do presente. É do hoje que partimos rumo ao passado, uma ponte na busca de novos sentidos.

\section{ESCRITAS DE SI: MARCAS AUTOBIOGRÁFICAS NA WEB}

Com o incremento dessas tecnologias da informação na história dos sujeitos, abre-se um leque de possibilidades para pensar as técnicas utilizadas pelos usuários da rede para criarem os seus espaços de interlocução, como nos declara Lévy (1999, p. 119): “os dispositivos informativos penetram e se entrecruzam no mais íntimo do sujeito”. Temos assim, a transição das escritas do "eu", com seus segredos e intimidades que antes eram reservadas às páginas de um confidencial "diário", para o espaço virtual, percorrendo o mundo nas páginas da web. Essa reflexão convida uma maneira diferenciada para pensar a história, permitindo ao historiador, registrar a importância das memórias da internet assim como as escritas dos sujeitos históricos. Nessa passagem do antigo diário de um "eu" reservado e misterioso às confissões públicas no diário virtual, é possível observar que os sujeitos põem em xeque o secreto, propondo uma interlocução sem eleger necessariamente um destinatário para as suas escritas. 
Mas, o que leva um usuário a optar por tornar pública a sua experiência, inclusive, a mais íntima? Ora, se muda o suporte da escrita de um diário (do papel para a tela do computador), vários objetivos e funções permanecem. Alberca (2000) nos ajuda a pensar que a escrita e os motivos que levam alguém a escrever um diário envolvem funções terapêuticas para desabafar, contar os desassossegos da alma; funções éticas - para guardar a memória dos momentos exemplares que se referem à boa conduta humana; e funções estéticas - para conservar o diário como ato de escrita, como expressão da cultura gráfica de seu tempo, pois a prática diarista liga-se à necessidade de introspecção, de comunicação, para contar experiências, para relacionar-se com um interlocutor ideal.

Dessa forma, é possível observar que instauram-se novas práticas de sociabilidade assim como escritas pessoais que registram uma nova época de escritura. Ao invés de desenvolver escritas no silêncio e na solidão do espaço privado (o diário pessoal escrito no quarto, em surdina, por exemplo), observam-se as escritas de fora (os diários pessoais que são tornados públicos, pela exposição na rede, por exemplo), visando à captação dos olhares alheios, ressaltando a construção de si na sociedade contemporânea.

Eco $^{12}$ encaminha uma reflexão sobre os suportes modernos, parecendo-nos criados mais para a difusão da informação do que para sua conservação. Assim, o autor complementa, dentro de alguns séculos a única forma de ter notícias sobre o passado, quando todos os suportes eletrônicos tiverem sido desmagnetizados, continue sendo um livro impresso. Vidal (2000) ratifica que a guarda dos documentos antigos e presentes para a pesquisa e escrita em história da educação é uma imposição, uma determinação, precisando ser considerada. A obsolescência é uma preocupação que também precisa ser pensada, devido ao aparecimento de novos produtos automaticamente substituídos. A autora sugere alguns aspectos para serem analisados no campo historiográfico: o interesse pelo cotidiano, pela materialidade dos objetos culturais; a necessidade do descarte assim como o da referência documental, e a busca por profissionais sensíveis às questões de preservação da memória impondo diálogos com o historiador que também precisa se enquadrar no desafio de compreender as novas tecnologias.

\section{CONSIDERAÇÕES FINAIS}

Se vivemos num impacto da tecnologia com variadas ordens documentais e de uma enorme ampliação de memórias históricas, não é possível permanecer com olhos vendados

${ }^{12}$ Publicado num artigo de Umberto Eco no The New York Times em 26/04/2009. Tradução: Luiz Roberto Mendes Gonçalves. 
para o universo contemporâneo. Destarte, Nunes (2005) enfatiza que cada vez mais há uma preferência manifesta pelos pesquisadores em privilegiar como objeto de investigação as práticas culturais, seus sujeitos e seus produtos, tomados estes últimos em sua materialidade de objetos culturais. Nesse sentido, proponho novos olhares no campo do pesquisador em história da educação que não poderá desconsiderar as questões teórico-metodológicas utilizadas por essas novas vertentes historiográficas.

Mignot (2006) nos ajuda a pensar que mergulhar em arquivos pessoais tem permitido valorizar a escrita na vida, instigando cada vez mais a surpreender tanto os indivíduos que escrevem como os contextos e as motivações que os levam a aprisionar o vivido em folhas de papel. Assim, num tempo de tecnologias, as folhas de papel são trocadas e substituídas pelos monitores, estas máquinas de registro não apenas fixam, num suporte reprodutor, aquilo que os olhos vêem e os ouvidos escutam, mas também duplicam a capacidade humana de ouvir e ver. Nesse sentido, complementa Vidal (2000), não há como recusar o produto eletrônico, porque a linguagem virtual tem permitido a construção de outras práticas de leitura e escrita, que oferecem maneiras novas de organizar, hierarquizar e distribuir a informação e combinações de estímulos visuais e sonoros impensáveis para o suporte de papel.

Ouso me inspirar em dois episódios da obra épica Os Lusíadas $^{13}$ do poeta-historiador, Luis de Camões, quando o renascentista canta o passado português. Primeiramente, ao retratar o momento em que o ocidente (os lusitanos), se encontra com o oriente (Cabo das Tormentas), uma possível metáfora do encontro entre o mundo conhecido ocidental e o universo oriental desconhecido pelo povo português, para nos ajudar a pensar um estudo das escritas ordinárias nos espaços virtuais como fontes historiográficas desconhecidas no campo da história da educação; e depois, relembrar o momento glamoroso em que os heróis lusitanos, após as suas conquistas e batalhas, foram surpreendidos na ilha dos Amores, território prodigioso para a conquista, ao percebermos nesses novos espaços, territórios abertos para pensar a história da educação brasileira.

Assim sendo, a minha expectativa é de suscitar questionamentos que nos levem a refletir sobre as escritas que falam de si na internet, possibilitando pensar esses discursos como fontes historiográficas, buscando contribuir para a pesquisa em história da Educação.

${ }^{13}$ Ver CAMÕES, Luis. Os Lusíadas. Rio de Janeiro: Ed. Klick, 1999. 


\section{REFERÊNCIAS}

ALBERCA, Manuel. La escritura invisible: testimonios sobre el diário íntimo. Madrid: Sendoa, 2000.

BENJAMIN, Walter. Obras Escolhidas I: Magia e Técnica, Arte e Política. Tradução de Sérgio Paulo Rouanet. São Paulo: Brasiliense, 1994.

BOSI, Alfredo. História Concisa da Literatura Brasileira. São Paulo: Cultrix, 2004.

BOSI, Ecléa. Memória e sociedade, lembrança de velhos. São Paulo: Companhia das Letras, 2004.

BURKE, Peter. Popular culture in early modern Europe. London: Maurice Temple Smith, 1978.

CERTEAU, Michel de. A escrita da história. Rio de Janeiro: Forense Universitária, 1982.

CHARTIER, Roger. A história cultural entre práticas e representações. Lisboa: Difel, 1987.

A ordem dos livros: leitores, autores e bibliotecas na Europa entre os séculos XVI e XVIII. Brasília: Universidade de Brasília, 1999.

Práticas da leitura. São Paulo: Estação Liberdade, 1997. Unesp, 2007.

Inscrever e apagar: cultura escrita e literatura- séculos XI-XVIII, São Paulo: Ed.

CUNHA, Maria Teresa Santos; BASTOS, Maria Helena Câmara; MIGNOT, Ana Chrystina Venancio (orgs). Refúgios do eu: Educação, história e escrita autobiográfica. Florianópolis: Ed. Mulheres, 2000.

FARIA FILHO, Luciano Mendes de; BERTUCCI, Liane Maria. Experiência e Cultura: contribuições de E. P. Thompson para uma história social da escolarização. Currículo sem fronteiras, v. 9, n. 1, p. 10-24, jan./jun. 2009.

FREITAS, Maria Tereza de Assunção. Leitura e escrita de adolescentes na internet e escola. Belo Horizonte: Autêntica, 2005.

GINZBURG, Carlo. Mitos, emblemas, sinais: morfologia e história. São Paulo: Cia das letras, 1989.

LE GOFF, Jacques. Documento/Monumento. In: Enciclopédia Einaudi. Lisboa: Imprensa Nacional: Casa da Moeda, 1984.

História e memória. Campinas, SP: Ed. Da Unicamp, 1990.

LEJEUNE, Philippe. Le pacte autobiographique. Paris: Seuil (Poétique), 1975. 
LÉVY, Pierre. Cibercultura. Tradução de Carlos Irineu da Costa. São Paulo: Ed. 34, 1999.

MIGNOT, Ana Chrystina Venâncio. Da gaveta à vitrine: exposições sobre a escrita. In: SOUZA, Elizeu Clementino de (org.). Autobiografias, histórias de vida e formação: pesquisa e ensino. Porto Alegre: EDIPUCRS, 2006.

MUZART, Zahidé Lupinacci. Do navegar e de navegantes. Congresso Nacional da Abralic, Florianópolis, 1998.

NUNES, Clarice. Historiografia da educação e fontes. In: Pesquisa em história da educação no Brasil. Rio de Janeiro: DP\&A editora, 2005.

ROLLAND, Dennis. Internet e história do tempo presente. Estratégias de memória e mitologias políticas. Revista Tempo, n. 16, vol. 8. RJ: UFF, 2004. Disponível em: <http: //www.historia.uff.br/tempo/artigos>. Acesso em: set. 2015.

VENDRYÉS, J. Le Language, introduction linguistique à I'histoire. Paris: le Renaissance du Livre, 1986.

VIDAL, Diana Gonçalves. Fim do mundo do fim: avaliação, preservação e descarte documental. In: FARIA FILHO, Luciano Mendes de (org.). Arquivos, fontes e novas tecnologias: questões para a história da educação. Campinas, SP: Autores Associados, 2000.

VIÑAO, Antonio. Las autobiografias, memórias y diários como fuente histórico-educativa: tipologia e usos. Conferencia de Verano de la Universidad Complutense, Espanha, 1997. 